УДК 339.13:796 (571.62)

ББК 65.497.7:75.48

ОСОБЕННОСТИ ПОТРЕБИТЕЛЬСКИХ ПРЕДПОЧТЕНИЙ ЖИТЕЛЕЙ Г. ГОМЕЛЯ В ВЫБОРЕ ФИЗКУЛЬТУРНО-ОЗДОРОВИТЕЛЬНЫХ УСЛУГ

\author{
Е. В. ГУСИНЕЦ \\ e_gusinets@inbox.ru \\ старший преподаватель кафедры «Теории и методики физической культуры» \\ Гомельский государственный университет им.Ф.Скорины \\ Гомель, Республика Беларусь
}

Статья посвящена определению спроса на физкультурные услуги через выявление потребительских предпочтений населения 2. Гомеля в занятиях физкультурой и спортом. Актуальность исследования обусловлена возросшим усилением роли физической культуры и спорта в жизни современного общества. Основной иеелью исследований является маркетинговая оченка субъективно-мотиваџионных характеристик потребителей физкультурно-оздоровительных услуг различных возрастных групп.

Ключевые слова: физкультурно-оздоровительные услуги, рынок фитнес-услуг, население, потребительские предпочтения, здоровье, физическая культура и спорт

\title{
FEATURES OF CONSUMER PREFERENCES OF INHABITANTS OF GOMEL IN THE CHOICE OF SPORTS AND IMPROVING SERVICES
}

\section{E. V. GUSINETS}

lecturer of department of «Theories and techniques of physical culture technique»

Francisk Skorina Gomel State University

Gomel, Republic of Belarus

The demand for sports services through detection of consumer preferences in exercises and sport of Gomel population is determinated in the article. The relevance of a research is caused by the increased strengthening of a role of physical culture and sport in life of modern society. The main aim of researches is marketing assessment of subjective and motivational characteristics of consumers of sports and improving services of various age groups

Keywords: sports and improving services, market of fitness services, population, consumer preferences, health, physical culture and sport

\section{ВВЕДЕНИЕ}

В связи с постоянным поступательным ростом средней продолжительности жизни людей в мире, а, соответственно, и повышением границ пенсионного возраста, постепенно повышается и возрастной порог активной деятельности населения. Такие современные тенденции предъявляют к людям высокие требования к состоянию физического здоровья, о котором многие начинают задумываться уже в юном возрасте [1]. С другой стороны, в связи с ростом внедрения IT-технологий в трудовой процесс современного человека постоянно падает его двигательная активность, что в свою очередь приводит к снижению уровня физического развития, функциональной подготовленности, физической и умственной работоспособности и показателей здоровья в целом. Этот факт сегодня способствует лучшему пониманию ценности здоровья, как личного капи- 
тала отдельно взятого человека [2]. При этом, большинству развитых стран мира свойственна особая забота о человеческих ресурсах страны, от качества и количества которых напрямую зависит состояние экономики. США сегодня является страной, в которой более $40 \%$ населения вовлечено в регулярные занятия физической культурой и спортом [3], в Германии это показатель превышает 60 \% [4], а в России - чуть более 31 \% [5]. Что касается Республики Беларусь, то в нашей стране, в настоящее время, регулярным физкультурно-оздоровительным и спортивным занятиям отдают предпочтение лишь $21 \%$ населения [6].

Удовлетворение потребности населения в систематических занятиях физической культурой и спортом с целью укрепления его здоровья - задача государственного масштаба, которая будет оставаться актуальной всегда.

В этой связи возникает объективная необходимость эффективного развития физкультурно-оздоровительной и спортивно-массовой работы на благо всего человечества: осознание значимости участия большей части населения в физкультурно-оздоровительных программах, закрепление норм и правил здорового образа жизни в современном обществе [7].

\section{РЕЗУЛЬТАТЫ И ИХ ОБСУЖДЕНИЕ}

В целях определения особенностей спроса населения г. Гомеля на физкультурнооздоровительные услуги было организовано и проведено исследование на основе анкетирования, в котором приняли участие 480 гомельчан (207 мужчин и 273 женщины) разного возраста, проживающих в различных районах города. Анкетирование проводилось в печатной и электронной форме с использованием интернет-технологии «Google forms». Исследование позволило определить набор востребованных физкультурных услуг и популярных мест их получения, а также факторы, оказывающие наибольшее влияние на предпочтения жителей в выборе физкультурно-оздоровительных услуг.

В качестве основных результатов проведенного исследования были выбраны следующие количественные и качественные характеристики, характеризующие предпочтения населения:

- отношение граждан к собственному здоровью и способам его улучшения;

- частота занятий физической культурой и спортом в настоящее время и предыдущий опыт физкультурно-спортивной деятельности в детстве;

- целевое назначение физкультурно-оздоровительных и спортивных занятий и перечень наиболее востребованных их видов среди населения;

- состав личного окружения при посещении физкультурно-оздоровительных занятий;

- основные причины, препятствующие систематическим занятиям физическими упражнениями или сдерживающие интерес к подобным занятиям;

- основные предпочтения в форме получения физкультурно-оздоровительных услуг (платная или бесплатная), а также в уровне оплаты за их потребление;

- основные предпочтения в посещении спортивных мероприятий и физкультурно-спортивных сооружений для самостоятельных занятий;

- основные предпочтения в строительстве новых видов физкультурно-спортивных сооружений по месту жительства населения. 
Результаты исследования показывают, что большинство опрошенных жителей г. Гомеля (90\%) заботятся о своем здоровье. Внимательное отношение к собственному здоровью постепенно становится одной из важнейших ценностных установок человека в современном белорусском обществе. При этом следует отметить, что, отвечая на вопрос анкеты «Что Вы обычно делаете для улучшения своего здоровья?», респонденты давали ответы, не всегда соответствующие ранее заявленной заботе о собственном здоровье (таблица 1).

Таблица 1 - Результаты ответов респондентов на вопрос «Что Вы обычно делаете для улучшения своего здоровья?»

\begin{tabular}{|l|l|l|}
\hline № & Вариант ответа на вопрос & Результат \\
\hline 1 & прогуливаюсь на свежем воздухе & $57,0 \%$ \\
\hline 2 & не курю & $50,9 \%$ \\
\hline 3 & стараюсь следить за своим рационом питания & $39,7 \%$ \\
\hline 4 & занимаюсь регулярными физическими упражнениями & $39,3 \%$ \\
\hline 5 & $\begin{array}{l}\text { принимаю различные витамины и (или) биологически активные до- } \\
\text { бавки }\end{array}$ & $32,0 \%$ \\
\hline 6 & слежу за режимом сна и отдыха (сплю не менее 7-8 часов) & $30,4 \%$ \\
\hline 7 & $\begin{array}{l}\text { почти не употребляю алкоголь (могу позволить себе выпить только в } \\
\text { праздники) }\end{array}$ & $27,2 \%$ \\
\hline 8 & не употребляю сладкие напитки (Соса соlа, Sprite, Рерsі и др.) & $27,0 \%$ \\
\hline 9 & $\begin{array}{l}\text { регулярно пью достаточное количество воды (не менее 8 стаканов в } \\
\text { сутки) }\end{array}$ & $23,9 \%$ \\
\hline 10 & не употребляю алкоголь (никогда, даже в праздники) & $20,8 \%$ \\
\hline 11 & посещаю лечебные санатории, базы отдыха & $13,7 \%$ \\
\hline 12 & регулярно хожу в баню & $12,9 \%$ \\
\hline 13 & занимаюсь закаливанием и обливанием & $7,3 \%$ \\
\hline 14 & не употребляю напитки, содержащие кофеин (кофе, чай) & $5,4 \%$ \\
\hline 15 & ничего не делаю & $3,7 \%$ \\
\hline
\end{tabular}

Как видно из представленной таблицы 1 , менее 40 \% опрошенных следят за своим питанием и регулярно выполняют физические упражнения, лишь 50,9 \% опрошенных не курит и чуть более $20 \%$ никогда не употребляют спиртные напитки. Менее трети опрошенных уделяют достаточное внимание качеству своего сна и количеству употребляемой воды. Все эти факты свидетельствуют в пользу того, что современное общество, несмотря на высокий уровень информатизации, все еще недостаточно серьезно относится к своему здоровью, несмотря на свои «громкие» заявления о его важности в их жизни.

Массовый опрос населения позволил определить основной состав потребностей потенциальных потребителей физкультурно-оздоровительных услуг через выявление приоритетных целей занятий физкультурой и спортом.

Таблица 2 - Основные цели занятий физической культурой и спортом жителей г. Гомеля

\begin{tabular}{|c|l|c|}
\hline$№$ & Цель занятия ФКиС & Результат \\
\hline \hline 1 & Хорошее самочувствие и настроение & $52,4 \%$ \\
\hline 2 & Укрепить здоровье & $46,6 \%$ \\
\hline 3 & Иметь красивое телосложение & $44,1 \%$ \\
\hline
\end{tabular}


Окончание таблицы 2

\begin{tabular}{|c|l|c|}
\hline 4 & Просто отдохнуть & $22,3 \%$ \\
\hline 5 & Избавиться от избыточного веса & $20 \%$ \\
\hline 6 & Желание уйти от повседневного однообразия & $15,8 \%$ \\
\hline 7 & Другие цели & $10,4 \%$ \\
\hline 8 & Соответствовать современному образу жизни и моде & $9,7 \%$ \\
\hline 9 & Составить компанию и пообщаться с друзьями & $9,7 \%$ \\
\hline
\end{tabular}

Как видно из таблицы 2, самой главной для себя целью занятий физической культурой и спортом (более 52\% опрошенных) считают достижение хорошего самочувствия и настроения; укрепление здоровья - 46,6\% и желание иметь красивое телосложение $44,1 \%$ являются второй и третьей по значимости целью регулярных занятий физическими упражнениями.

Таким образом, посредством определения основных целей занятий физкультурой населения было выявлено, что в г. Гомеле физкультурные услуги выполняют важную роль в практической реализации многообразия социальных функций физической культуры, которые удовлетворяют не только потребность личности в улучшении здоровья, но удовлетворяют эмоциональные, рекреационные и коммуникативные потребности, потребности в улучшении телосложения, в создании красивой внешности, потребности соответствия модным тенденциям и т. д.

В ходе исследования выяснилось, что $60,1 \%$ опрошенных в детстве занимались в физкультурно-спортивных секциях, клубах или детско-юношеских спортивных школах, причем 28 \% из них более одного года. Так наиболее востребованными видами спорта в г. Гомеле респондентами были отмечены: легкая атлетика, плавание и баскетбол и единоборства (борьба, каратэ, бокс и др.). Также следует обратить особое внимание на то, что в г. Гомеле $27,4 \%$ опрошенных вообще не занимались регулярно физкультурой и спортом в детстве, а 4,8 \% имели освобождение от занятий физической культурой и спортом по состоянию здоровья (рисунок 1).

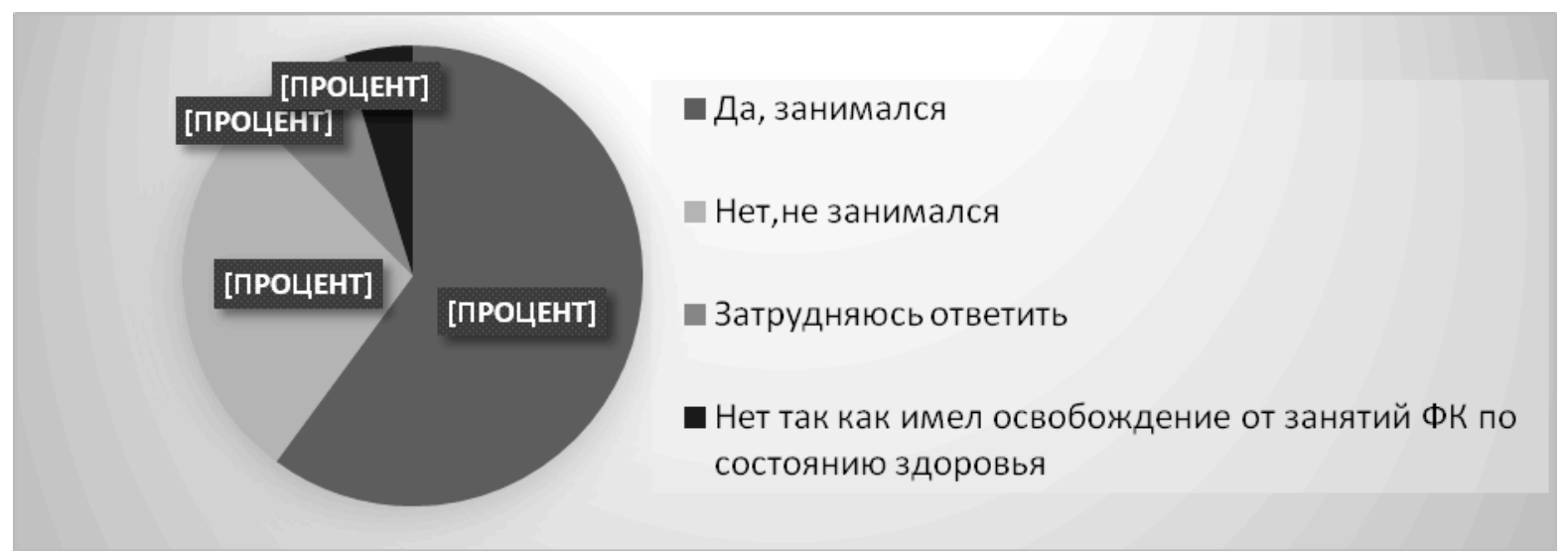

Рисунок 1 - Результаты ответов респондентов на вопрос «Занимались ли Вы в детстве (до 16 лет) каким-либо видом спорта или физическими упражнениями помимо уроков ФК в школе?»

Анализ результатов, полученных в ходе опроса населения г. Гомеля по структуре предпочтений к видам занятий физической активностью выявил особенности, 
заключающиеся в дифференциации потребления физкультурных услуг, по сезонам (рисунки 2, 3, 4).

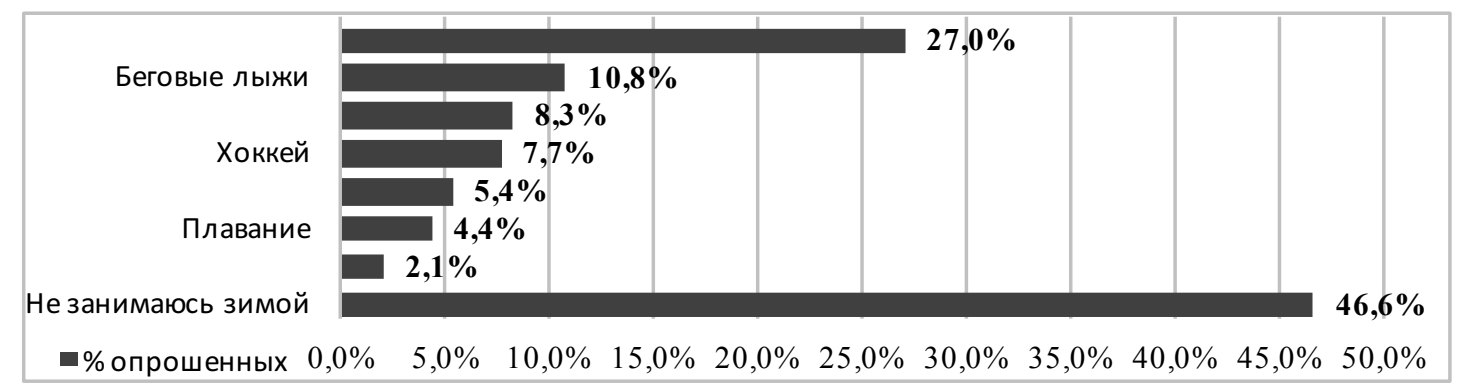

Рисунок 2 - Результаты ответов респондентов на вопрос «Каким видом спорта или физкультуры Вы занимаетесь в настоящее время (зимнее время года)?»

Так в зимнее время года наиболее востребованы (рисунок 2):

- катание на коньках $(27 \%)$;

- катание на беговых лыжах (10,8\%);

- игра в футбол $(8,3 \%)$;

- катание на горных лыжах $(5,4 \%)$.

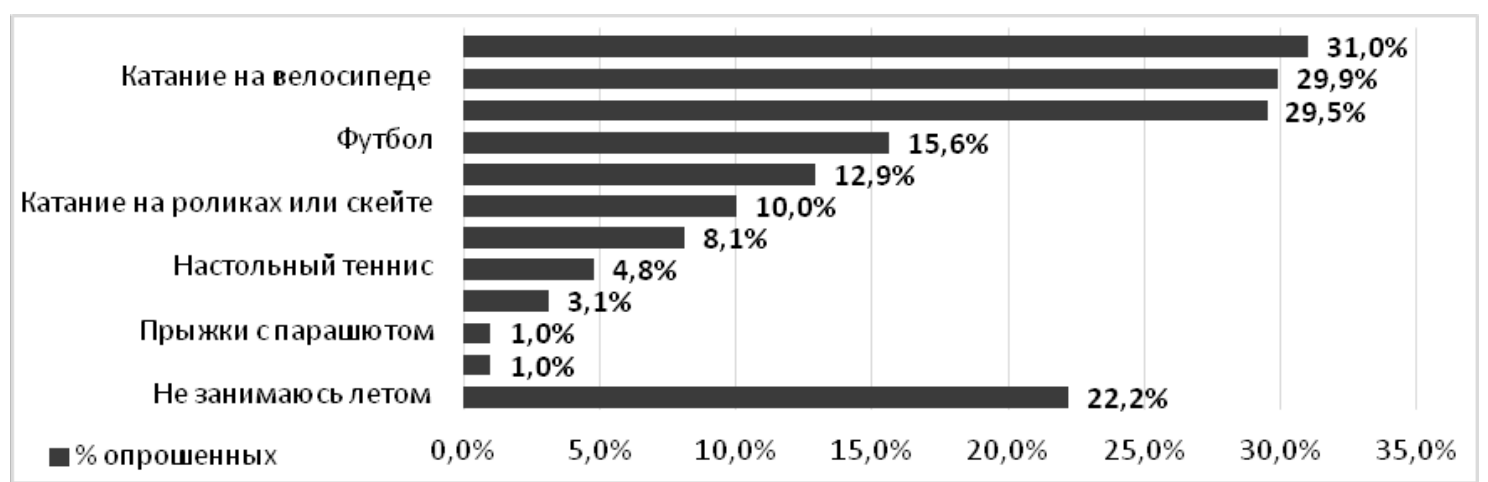

Рисунок 3 - Результаты ответов респондентов на вопрос «Каким видом спорта или физкультуры Вы занимаетесь в настоящее время (летнее время года)?»

Летом наиболее популярны (рисунок 3):

- оздоровительный бег (29,9\%);

- катание на велосипеде (29,9\%);

- плавание $(29,5 \%)$

- игровые виды спорта (футбол - 15,6\%; волейбол - 12,9\%). 


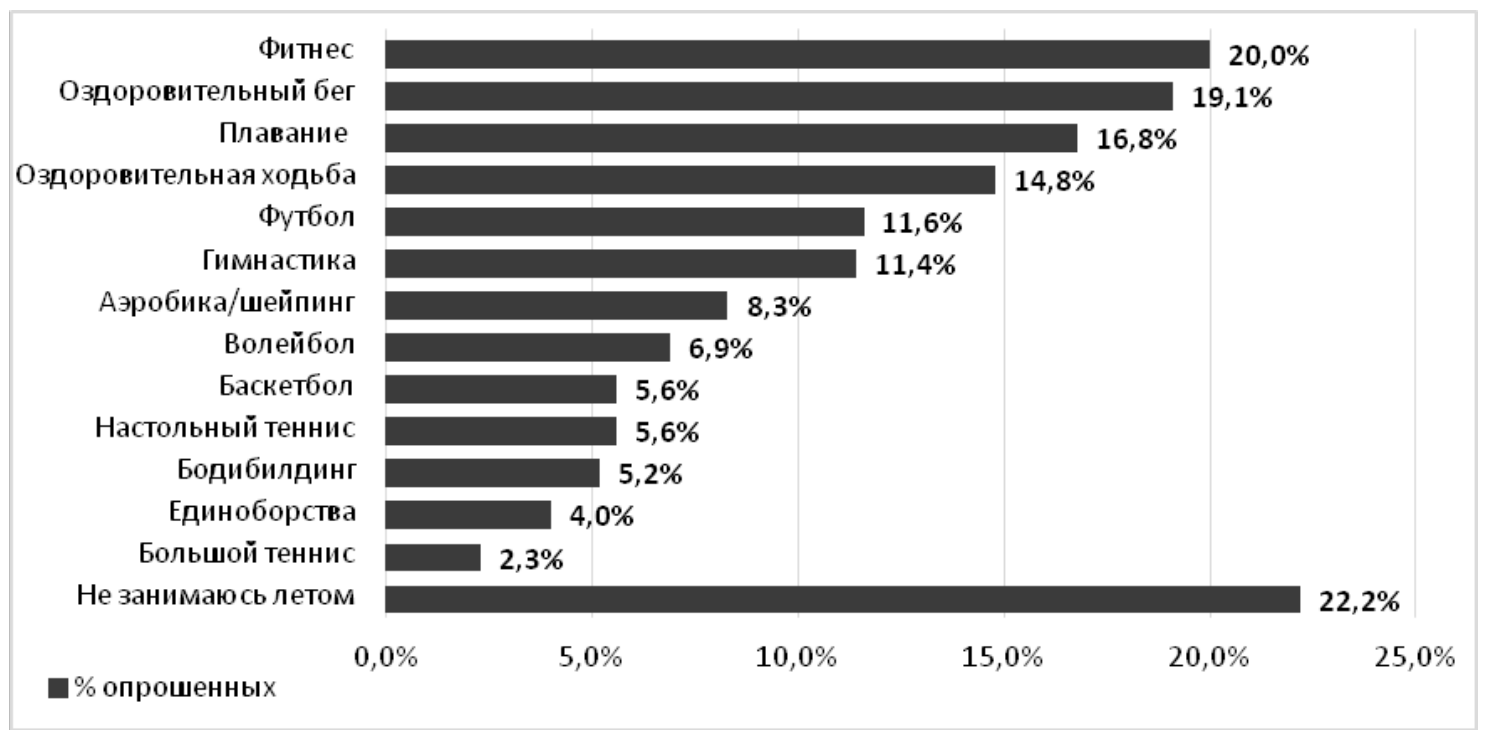

Рисунок 4 - Результаты ответов респондентов на вопрос «Каким видом спорта или физкультуры Вы занимаетесь в настоящее время (вне зависимости от времени года)?»

В течение всего года наиболее популярны (рисунок 4):

- посещение фитнес-клубов и тренажерных залов (44,9\% в сумме): фитнес (20\%), гимнастика $(11,4 \%)$, аэробика и занятия шейпингом $(8,3 \%)$ и бодибилдинг $(5,2 \%)$;

- оздоровительный бег (19,1\%);

- плавание в бассейне и природных водоемах $(16,8 \%)$;

- оздоровительная ходьба $(14,8 \%)$;

Как видно из полученных данных сезонная предпочтительность в выборе физкультурно-спортивных занятий гомельчан имеет место быть; особенно это касается исключительно зимних и летних видов спорта и активного отдыха, однако посещение фитнес-клубов и тренажерных залов, занятия игровыми видами спорта, оздоровительная ходьба и бег не теряют свою востребованность круглый год.

Структура потребления физкультурно-оздоровительных услуг населением г. Гомеля свидетельствует о приоритетном выборе в пользу платных: им отдали предпочтение 39,9\% респондентов, бесплатным - почти столько же - 38,7\%, а 21,2\% респондентов не потребляют данные услуги ни в одной из форм. Необходимо отметить, что при постепенном повышении уровня реальных доходов населения страны, несомненно, будет увеличиваться и число жителей города, занимающихся в фитнесцентрах, клубах, студиях и секциях на платной основе (при условии своевременного повышения качества и разнообразия предоставляемых услуг).

Как видно из таблицы 3 , фактические ежемесячные расходы жителей Гомеля на физкультурно-спортивные занятия различны. Возможность тратить на физкультурные услуги 5-10 рублей в месяц есть у 9,3\% опрошенных респондентов, в то время, как только $3 \%$ жителей областного центра могут позволить себе расходы на эти услуги, превышающие 70 белорусских рублей или около 35 долларов США; при этом более 50\% опрошенных ежемесячно тратят на данные услуги 11 - 40 рублей ежемесячно. 
Таблица 3 - Ежемесячные расходы жителей г. Гомеля на занятия физкультурой и спортом и совокупный месячный доход на всю семью в рублях (BYN)

\begin{tabular}{|c|c||c|c|}
\hline $\begin{array}{l}\text { Затраты на физкультурно- } \\
\text { оздоровительные услуги } \\
\text { (в рублях ВYN) }\end{array}$ & $\begin{array}{c}\text { Результат, } \\
\text { в \% }\end{array}$ & $\begin{array}{l}\text { Совокупный месячный доход } \\
\text { на всю семью в рублях (ВYN) }\end{array}$ & $\begin{array}{c}\text { Результат, в } \\
\%\end{array}$ \\
\hline \hline $5-10$ & 9,3 & До 265 & 3,1 \\
\hline $11-15$ & 10,2 & $265-400$ & 13,3 \\
\hline $16-20$ & 10,5 & $401-567$ & 15,4 \\
\hline $25-30$ & 17,4 & $568-767$ & 15,8 \\
\hline $31-40$ & 12,3 & $768-1133$ & 20,8 \\
\hline $41-50$ & 8,8 & $1134-1500$ & 14,1 \\
\hline $51-70$ & 5,1 & $1500-2000$ & 7,7 \\
\hline Более 70 & 3 & более 2000 & 1,7 \\
\hline
\end{tabular}

Из таблицы 3 видно также, что более 50\% опрошенных имеют совокупный месячный доход на всю семью в диапазоне от 400 до 1133 рублей (BYN) и представляют собой основную долю потребителей на рынке физкультурно-оздоровительных услуг. Поэтому запланированный правительством Республики Беларусь планомерный рост средней заработной платы несомненно окажет положительное влияние и на спрос горожан на более качественные физкультурно-оздоровительные услуги, увеличивая, тем самым, и количество потребляемых услуг на душу населения и соответственно, общие затраты на их потребление.

Зачастую многие люди не могут посещать физкультурно-спортивные сооружения и занятия физической культурой и спортом, ссылаясь на различные причины. Исследуя потребительские предпочтения жителей г. Гомеля, мы не могли обойти стороной и эту проблему. По данным проведенного исследования основными факторами, ограничивающими возможность занятий физкультурой и спортом, являются:

1) недостаток свободного времени - 65,3\% опрошенных;

2) недостаток требуемых денежных средств - 16,5\% опрошенных;

3 ) нет компании для совместного посещения, а мешает собственная лень $-14,9 \%$ опрошенных;

4) неудобное месторасположение мест для занятий - 12,4\% опрошенных;

5) не нуждаюсь в занятиях ФКиС - 3,9\% опрошенных;

6) нет объективных препятствий - 3,7 \% опрошенных;

7) проблемы со здоровьем - $1 \%$ опрошенных;

Как видно из приведенных результатов опроса гомельчан, основной причиной, препятствующей регулярным занятиям ФКиС является недостаток свободного времени (более 65\% опрошенных) и недостаток требуемых денежных средств (более 16\% опрошенных). На наш взгляд, такая ситуация говорит о том, что большинство тех, кто не занимается регулярными физическими упражнениями все-таки не считают эти занятия настолько важными и необходимыми для их здоровья, чтобы найти в своем жизненном расписании для них время и денежные средства. Кроме того, невысокий средний уровень доходов населения по отношению к среднеевропейскому вынуждает многих горожан искать себе дополнительную подработку, увеличивая, тем самым, продолжительность дневного труда, а иногда отказывая себе даже в полноценных выходных днях, которые можно было использовать для активного отдыха и восстановления.

Организация и проведение зрелищно-спортивных мероприятий было и остается сегодня действенным направлением в деле пропаганды физической культуры и спорта. Последнее десятилетие характеризуется значительным ростом числа проводимых 
спортивных соревнований и культурно-зрелищных мероприятий на стадионах и других спортивных сооружениях нашей республики и Гомеля, в частности.

На рисунке 5 представлены результаты опроса жителей г. Гомеля на предмет наиболее популярных и часто посещаемых зрелищно-спортивных мероприятий.

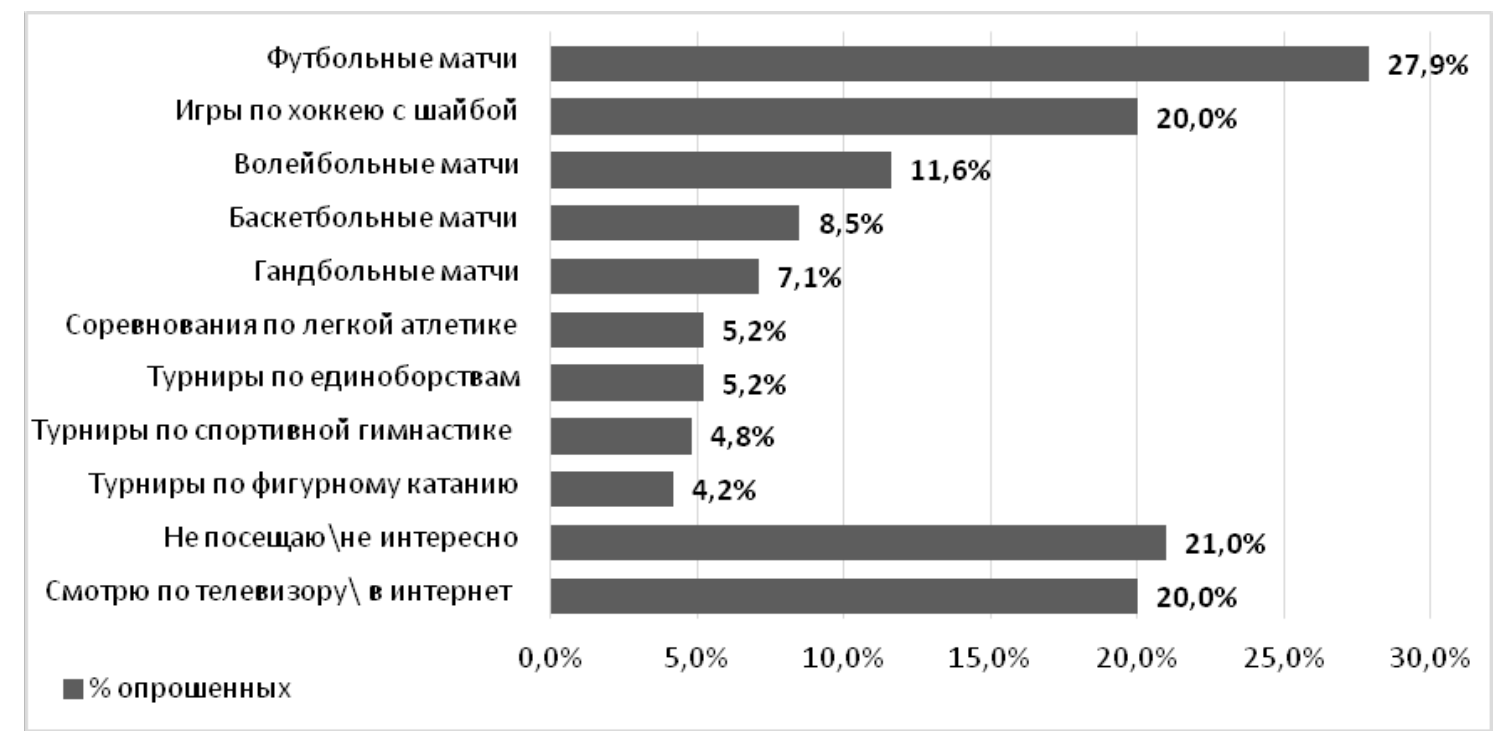

Рисунок 5 - Наиболее часто посещаемые зрелищно-спортивных мероприятия г. Гомеля в качестве болельщика (по данным анкетного опроса)

Результаты опроса, представленные на рисунке 5, показывают, что свыше 57\% гомельчан посещают матчи по командным игровым видам спорта, а турнирам по индивидуальным видам спорта отдают предпочтение лишь $20 \%$ горожан. Такое различие, на наш взгляд, продиктовано, прежде всего, тем, что футбол, хоккей, баскетбол, гандбол и волейбол являются самыми популярными видами спорта во всем мире, что, несомненно, оказывает влияние и на выбор белорусских болельщиков; кроме того, у местных клубов в представленных игровых видах спорта прекрасные традиции и регулярное высокое положение в турнирных таблицах высшей лиги: гомельский футбольный, волейбольный и хоккейный клубы в различные годы становились победителями и призерами Кубка Республики Беларусь и Чемпионата страны.

\section{ВЫВОДЫ}

В результате проведенного исследования установлено, что видимое стремление к физическому совершенству оказалось лишь внешним мотивом потребления, за которым, зачастую, прячется ожидание совершенно других результатов. В работе предпринята попытка использовать социологический опрос для определения ценностного потенциала и потребительских предпочтений жителей г. Гомеля, а также особенностей психологического личного профиля потребителей физкультурно-оздоровительных услуг.

Несмотря на всестороннюю поддержку физической культуры и спорта со стороны государственных органов управления, население городов далеко не всегда имеет возможность заниматься физическими упражнениями и активным отдыхом в доступной и удобной форме. Большая часть опрошенных не располагает достаточным временем для систематических занятий физической культурой и спортом в виду отсутствия востребованных видов физкультурно-оздоровительных услуг в шаговой доступности. 
В связи с этим необходимо принятие соответствующих мер, как со стороны правительства, так и со стороны органов исполнительной власти по созданию благоприятных условий для частного сектора экономики, заинтересованного в предоставлении подобных услуг населению. В решении данной проблемы особую роль должно сыграть государственно-частное партнерство, преимуществом которого является применение управленческих навыков бизнеса, лучшее знание рынка, большее стремление и заинтересованность частного сектора в получении прибыли, а также возможность внедрения современных технологий за счет дополнительного финансирования со стороны бизнеса.

Результаты проведенного массового опроса населения могут помочь в разработке региональной программы развития физкультурно-спортивных организаций, направленной не только на поддержание и активизацию культурно-развлекательного досуга граждан, но и на формирование и развитие концепции здорового образа жизни, основанной на массовом характере потребления физкультурных услуг различными категориями населения. Дальнейшие исследования будут направлены на изучение непосредственных потребителей физкультурных услуг: посетителей фитнесс-центров, тренажерных залов, бассейнов и спортивных комплексов с целью углубленной сегментации регионального рынка физкультурно-оздоровительных услуг, а также разработке практических рекомендаций по совершенствованию спортивно-оздоровительной работы в физкультурно-спортивных организациях на основе современных экономических подходов.

\section{СПИСОК ИСПОЛЬЗОВАННЫХ ИСТОЧНИКОВ}

1. Гусинец, Е. В. Физическая культура и спорт как социально-экономическое явление в национальной экономике Республики Беларусь / Е. В. Гусинец // Известия Гомельского государственного университета им. Ф. Скорины. - 2016. - № 5 (98). - С. 107-111.

2. Гусинец, Е. В. Физическая культура и спорт в экономике и жизни общества Республики Беларусь / Е. В. Гусинец, Н. С. Казанцева, Н. В. Дергунова // Современное состояние проблемы и перспективы развития отраслевой науки: материалы Всероссийской научной конференции с международным участием. Москва, МИИТ. - М.: Издательство «Перо», 2016. - С. 70-74.

3. Репкин, С. Б. Организационно-экономические аспекты развития спорта в США / С. Б. Репкин // Вестник Полоцкого государственного университета: экономические и юридические науки. -2015 . - № 6. - С. 15-23.

4. Репкин, С. Б. Анализ системы управления спортом в Германии / С. Б. Репкин // Бух. учет и анализ. - 2015. - № 3 (219).

5. Енченко, И. В. Анализ развития спортивно-оздоровительных услуг в России и за рубежом / И. В. Енченко, Е. В. Гусинец // Детско-юношеский туризм: образовательные технологии: сборник научных трудов по материалам III Междунар. науч.-практ. конф. Санкт-Петербург, 2017. - С. 77-86.

6. Гусинец, Е. В. Особенности рынка услуг физической культуры в Российской Федерации и в Республике Беларусь / Е. В. Гусинец, И.В. Енченко // Известия Гомельского государственного университета им. Ф. Скорины. - 2017. - № 2 (101). - С. 158-162. 7. Енченко, И. В. Современное состояние рынка фитнес-услуг / И. В. Енченко // Современный научный вестник. - 2016. - Т. 6. - № 2. 


\section{REFERENCES}

1. Gusinec, E. V. Fizicheskaja kul'tura i sport kak social'no-jekonomicheskoe javlenie v nacional'noj jekonomike Respubliki Belarus' / E. V. Gusinec // Izvestija Gomel'skogo gosudarstvennogo universiteta im. F. Skoriny. - 2016. - № 5 (98). - C. 107-111.

2. Gusinec, E. V. Fizicheskaja kul'tura i sport v jekonomike i zhizni obshhestva Respubliki Belarus' / E. V. Gusinec, N. S. Kazanceva, N. V. Dergunova // Sovremennoe sostojanie problemy i perspektivy razvitija otraslevoj nauki: materialy Vserossijskoj nauchnoj konferencii s mezhdunarodnym uchastiem. Moskva, MIIT. - M.: Izdatel'stvo «Pero», 2016. - C. 70-74.

3. Repkin, S. B. Organizacionno-jekonomicheskie aspekty razvitija sporta v SShA / S. B. Repkin // Vestnik Polockogo gosudarstvennogo universiteta: jekonomicheskie i juridicheskie nauki. - 2015. -№ 6. - S. 15-23.

4. Repkin, S. B. Analiz sistemy upravlenija sportom v Germanii / S. B. Repkin // Buh. uchet i analiz. - 2015. - № 3 (219).

5. Enchenko, I. V. Analiz razvitija sportivno-ozdorovitel'nyh uslug v Rossii i za rubezhom / I. V. Enchenko, E. V. Gusinec // Detsko-junosheskij turizm: obrazovatel'nye tehnologii: sbornik nauchnyh trudov po materialam III Mezhdunar. nauch.-prakt. konf. SanktPeterburg, 2017. - S. 77-86.

6. Gusinec, E. V. Osobennosti rynka uslug fizicheskoj kul'tury v Rossijskoj Federacii I v Respublike Belarus' / E. V. Gusinec, I.V. Enchenko // Izvestija Gomel'skogo gosudarstvennogo universiteta im. F. Skoriny. - 2017. - № 2 (101). - S. 158-162.

7. Enchenko, I. V. Sovremennoe sostojanie rynka fitnes-uslug / I. V. Enchenko // Sovremennyj nauchnyj vestnik. - 2016. - T. 6. - № 2.

Статья поступила в редакичию 15 октября 2018 года 